\title{
Rapport van de Adviescommissie belastingheffing van multinationals nader bekeken
}

\author{
Prof. mr. H. Koster*
}

\begin{abstract}
Op 15 april 2020 heeft de Adviescommissie belastingheffing van multinationals haar rapport getiteld ' $O p$ weg naar balans in de vennootschapsbelasting. Analyses en aanbevelingen' gepubliceerd. In dit artikel bespreekt de auteur dit rapport.
\end{abstract}

\section{Inleiding}

Op 15 april 2020 heeft de Adviescommissie belastingheffing van multinationals (hierna: de commissie) haar rapport getiteld 'Op weg naar balans in de vennootschapsbelasting. Analyses en aanbevelingen' (hierna: het rapport) verstuurd aan de Staatssecretaris van Financiën. Het rapport van de commissie bevat drie hoofdaanbevelingen. Ten eerste adviseert de commissie om structureel meer gegevens te verzamelen om het inzicht in de belastingafdracht van multinationals te vergroten. Ten tweede wijst de commissie op het belang van internationale samenwerking op het gebied van winstbelastingen, waarmee ongewenst strategisch gedrag van multinationals tegengegaan kan worden. Ten derde adviseert de commissie een basisvariant van unilaterale grondslagverbredende maatregelen. In het rapport presenteert de commissie daartoe een basispakket van zeven nationale maatregelen dat de belastingheffing voor multinationals volgens de commissie eerlijker maakt, waarbij het oog wordt gehouden op het vestigingsklimaat. Met dit pakket verwacht de commissie een extra belastingopbrengst van ongeveer EUR 600 miljoen per jaar. In dit artikel bespreek en onderzoek ik dit rapport.

\section{Achtergronden}

In september 2018 zegde de toenmalige Staatssecretaris van Financiën aan de Tweede Kamer toe om te komen met 'concrete bouwstenen en voorstellen voor verbeteringen en vereenvoudigingen van het belastingstelsel, waarbij knelpunten worden geduid en perspectief op oplossingen wordt geboden'. ${ }^{1}$ De reikwijdte van dit bouwsteneninitiatief zag in de kern op alle aspecten van het belastingstelsel, inclusief het belasten van digitale platforms, inkomsten uit aanmerkelijk belang en milieubelastingen, en dus niet specifiek alleen op de vennoot-

\footnotetext{
Prof. mr. H. Koster is verbonden aan de Universiteit Leiden, afdeling ondernemingsrecht, en aan de Universiteit van Dubai.

1. Brief aan Tweede Kamer van 18 september 2018, Fiscale moties en toe-
} zeggingen, kenmerk 2018-0000143859. schapsbelasting (hierna: $\mathrm{Vpb}$ ). In die periode ontstond evenwel specifiek over de $\mathrm{Vpb}$ rumoer in de media en de politiek over het feit dat een aantal Nederlandse multinationals in Nederland geen of weinig Vpb betaalt, waardoor de Vpb onder het vergrootglas kwam te liggen. ${ }^{2}$ Dit resulteerde in een parlementaire hoorzitting op 29 mei 2019, gevolgd door een debat in de Tweede Kamer. Naar aanleiding van deze discussies heeft de Tweede Kamer een motie aangenomen - de motie Omtzigt c.s. -, waarin de Staatssecretaris van Financiën is gevraagd een commissie van deskundigen in te stellen die adviseert over maatregelen om de belastingheffing over winsten van multinationals eerlijker te maken, met inachtneming van het feit dat Nederland aantrekkelijk blijft voor Nederlandse hoofdkantoren. ${ }^{3}$ Ter uitvoering van de motie Omtzigt c.s. heeft de Staatssecretaris van Financiën de Adviescommissie ingesteld, bestaande uit twaalf leden met diverse achtergronden en expertises, onder voorzitterschap van Bernard ter Haar. ${ }^{4}$ De staatssecretaris vulde de opdracht aan de commissie nader in door te vragen om advies over 'maatregelen die leiden tot grondslagverbreding van de vennootschapsbelasting, waarbij tegelijkertijd oog wordt gehouden voor het behoud van hoofdkantooractiviteiten in Nederland'. Het rapport bevat het advies van de commissie naar anleiding van deze vragen. Het bredere 'bouwstenen'-initiatief leek daarmee uit beeld te zijn geraakt. Recent publiceerde het ministerie evenwel een uitgebreid syntheserapport met een pakket van 169 beleidsopties onder de titel 'Bouwstenen voor een beter belastingstelsel'. ${ }^{5}$ Het syntheserapport benoemt de voornaamste knelpunten van ons belastingstelsel. Ook staat hier beschreven hoe deze knelpunten kunnen worden aangepakt. Het bouwstenentraject is een ambtelijk traject zonder politieke sturing met als doel om uitgewerkte beleidsopties op te leveren voor het volgende kabinet. ${ }^{6}$ Het syntheserapport

2. Bijv. J. Kleinnijenhuis \& K. Kuijpers, Shell betaalt in Nederland geen winstbelasting, Trouw 29 november 2018 en D. Metselaar, Belastingdruk grote bedrijven in tien jaar met kwart gedaald, NRC 24 oktober 2019.

3. Kamerstukken II 2018/19, 35110, nr. 11.

4. Stcrt. 2019, 50781 .

5. Brief aan Tweede Kamer van 18 mei 2020, rapporten 'Bouwstenen voor een beter belastingstelsel', kenmerk 2020-0000094149 (32140, nr. 71).

6. Brief aan Tweede Kamer van 18 mei 2020, rapporten 'Bouwstenen voor een beter belastingstelsel', kenmerk 2020-0000094149. 


\section{Maandblad}

Ondernemingsrecht

sluit voor de $\mathrm{Vpb}$ aan bij de voorstellen van de commissie-Ter Haar. $^{7}$

\section{Het rapport (van de Adviescommissie)}

\subsection{Belangrijkste punten van onderzoek}

Om tot een gebalanceerd advies te komen over grondslagverbredende maatregelen met oog voor het vestigingsklimaat, heeft de commissie vijf punten nader onderzocht. Het eerste punt betreft het belang van het fiscale vestigingsklimaat voor investeringen van bedrijven. Duidelijk is dat een lagere $\mathrm{Vpb}$ voor meer investeringen van bedrijven zorgt. Het exacte effect van de fiscaliteit en tot hoeveel economische activiteit dit leidt, laat zich evenwel lastig precies meten. Het tweede punt ziet op de vraag hoe Nederland zich verhoudt tot andere landen. De commissie heeft daartoe extern onderzoek laten uitvoeren, waarin vijftien geselecteerde landen, waaronder Nederland, onderling zijn vergeleken ten aanzien van de onderscheidende karakteristieken van met name hun winstbelastingstelsels. ${ }^{8}$ Daaruit blijkt onder andere dat op het vlak van verrekenprijzen en verliesverrekening Nederland afwijkt van wat in veel andere landen gebruikelijk is.

Het derde punt betreft de vraag hoe de Vpb zich heeft ontwikkeld door de jaren heen en ten opzichte van andere landen. De commissie heeft daartoe de ontwikkeling van Vpb-ontvangsten in Nederland gedurende de afgelopen twintig jaar onderzocht. De conclusie luidt dat sprake is van een lichte daling van de Vpb-ontvangsten - als percentage van het bbp - over de afgelopen twintig jaar. In zijn algemeenheid geldt evenwel dat Nederland een Vpb-opbrengst heeft die boven het OESOgemiddelde ligt. Het vierde punt ziet op de vraag hoeveel $\mathrm{Vpb}$ multinationals betalen in verhouding tot andere soorten bedrijven. Het antwoord luidt dat de relatie over de periode 2010-2017 stabiel is. Multinationals nemen in 2017 EUR 11,7 miljard van de Vpb-afdracht voor hun rekening, ofwel $51 \%$ van het totaal. Over de periode 2010-2017 is het beeld grofweg hetzelfde.

Het vijfde punt betreft de vraag wat knelpunten in de Vpb zijn die kunnen bijdragen aan een onevenwichtige belastingaf-

7. Het syntheserapport bevat een aanvullende beleidsoptie die ziet op het verder ontmoedigen van doorstroomactiviteiten. De afgelopen jaren zijn er al maatregelen genomen die het minder aantrekkelijk maken om doorstroomactiviteiten via Nederland te organiseren. Zo treedt per januari 2021 de conditionele bronbelasting op rente en royalty's naar laagbelastende landen in werking. Een stap verder in die richting zijn aanpassingen om dividenduitkeringen naar laagbelastende landen verder te ontmoedigen. In het syntheserapport wordt opgemerkt dat de keerzijde van deze maatregelen is dat daarmee ook de belastingdruk stijgt van bedrijven die naast doorstroomactiviteiten ook reële activiteiten in Nederland hebben.

8. Zie het door advieskantoor PwC opgestelde rapport 'Comparative analysis on taxation multinationals' en het Addendum daarbij. Om de juistheid en objectiviteit ten aanzien van de veelal technische onderwerpen te kunnen waarborgen, heeft de commissie het International Bureau of Fiscal Documentation (hierna: IBFD) gevraagd het rapport van $\mathrm{PwC}$ nader te beoordelen. Het commentaar van het IBFD is meegenomen bij het opstellen van het definitieve rapport. dracht van multinationals. Als knelpunten van het huidige stelsel noemt de commissie onder meer:

1. mogelijkheden tot winstverschuiving naar laagbelastende landen zonder substantiële wijzigingen in de investeringsstructuur;

2. belastingheffing over een winst die potentieel afwijkt van de totale geconsolideerde winst, met als gevolg dubbele belastingheffing of belastingheffing over minder dan de volledige winst;

3. asymmetrie tussen (de locatie van) aftrekbare kosten en (de locatie van) belastbare baten voor hoofdkantoren van multinationals;

4. mogelijkheden tot winstverschuiving door de keuze voor eigen of vreemd vermogen bij financiering binnen concern;

5. een suboptimale vermogensstructuur op concernniveau; en

6. prikkel voor belastingconcurrentie tussen landen.

\subsection{Vestigingsklimaat}

Het rapport gaat ook in op het vestigingsklimaat. Zo wordt aangehaald dat in de Global Competitiveness Index van het World Economic Forum van 2019, die wordt opgebouwd uit twaalf thematische pijlers, Nederland op de vierde positie staat. Nederland scoort hoog op de mate van openheid en dynamiek van de economie (tweede positie in de ranking), de fysieke en digitale infrastructuur (vierde positie) en de stabiliteit van het macro-economisch beleid (eerste positie). Ook onze relatief efficiënte overheid met goed functionerende instituties (vierde positie) en een zeer goed opgeleide beroepsbevolking (vierde positie) dragen bij aan de hoge ranking. Aandachtspunten in 2019 waren achterblijvende R\&D-investeringen en de mismatch tussen vraag en aanbod op de arbeidsmarkt. ${ }^{9}$

De commissie constateert in haar rapport dat de maatschappelijke meerwaarde van investeringen van bedrijven en een goed fiscaal vestigingsklimaat vooral zit in een hogere productiviteit, meer innovatie en hogere lonen. ${ }^{10}$ In het rapport wordt het vestigingsklimaat gedefinieerd als de aantrekkelijkheid van Nederland voor internationaal opererende bedrijven om zich hier te vestigen. Voor een goed vestigingsklimaat is onder meer van belang:

1. een goed opgeleide beroepsbevolking;

2. een goede en betrouwbare fysieke infrastructuur qua vervoer en communicatie;

3. een belastingstelsel dat het aanbieden van arbeid en het genereren van winst zo min mogelijk ontmoedigt;

4. een juridisch systeem dat zekerheid biedt, onder andere door een effectieve bescherming van de (intellectuele-)eigendomsrechten en het efficiënt en snel beslechten van mogelijke conflicten daarover;

5. efficiënte en voorspelbare regelgeving, zodat de markten in de economie goed werken;

9. Zie p. 25 van het rapport.

10. Zie p. 24 van het rapport. 
6. een efficiënt functionerende arbeidsmarkt waar mensen werken op plekken die aansluiten bij hun capaciteiten en waar fricties beperkt zijn;

7. stabiliteit. $^{11}$

Belastingheffing, en dan met name de Vpb, beïnvloedt de beslissingen van bedrijven over vestiging. Voor de vestigingsplaatskeuze van bedrijven is de hoeveelheid belasting die betaald moet worden bij een gegeven winstniveau bepalend (effectieve gemiddelde belastingdruk). Voor uitbreidingsinvesteringen hangt de keuze mede af van de belastingdruk op een extra verdiende euro (marginale belastingdruk). ${ }^{12}$ Daarnaast hebben verschillen in de fiscale behandeling van eigen en vreemd vermogen invloed op de financieringsstructuur van bedrijven. ${ }^{13}$ Thans komt $40 \%$ van de investeringen in Nederland uit het buitenland. ${ }^{14}$

Multinationale ondernemingen ${ }^{15}$ zijn bovendien verantwoordelijk voor een groot deel van de werkgelegenheid en de toegevoegde waarde van de Nederlandse economie (30\%), de helft daarvan betreft Nederlandse multinationals. ${ }^{16}$ Uit de Global Fortune 500 volgt dat in Nederland relatief meer hoofdkantoren statutair zijn gevestigd dan in veel andere landen. Twaalf bedrijven uit deze lijst hebben hun hoofdkantoor in Nederland, waarvan zes onderdeel zijn van de AEX. ${ }^{17}$ Een goed Nederlands vestigingsklimaat is dus zeer belangrijk.

De dividendbelasting kan op het niveau van de tophoudstervennootschap ook van invloed zijn op de vestigingslocatie van het fiscale/juridische hoofdkantoor. ${ }^{18}$ In het rapport wordt evenwel opgemerkt dat het Centraal Planbureau geen empirisch bewijs vindt van eventuele effecten van de dividendbelasting op de Nederlandse economie. ${ }^{19} \mathrm{Nu}$ deze heffing neerslaat bij buitenlandse aandeelhouders, zou dat niet onlogisch zijn volgens de commissie. ${ }^{20}$ Hier kan denk ik wel wat op worden afgedongen. $\mathrm{Nu}$ de dividendbelasting met name drukt op winstuitkeringen van een tophoudstervennootschap, kan de

11. Zie p. 24 van het rapport.

12. Zie p. 25 van het rapport.

13. Zie p. 25 van het rapport.

14. Zie p. 26 van het rapport.

15. Een definitie of afbakening van de ondernemingen die hieronder vallen, bevat het rapport niet.

16. Veelgenoemde ondersteunende hoofdkantooractiviteiten zijn: (1) legal \& company secretary, (2) treasury, (3) financial reporting \& control, (4) tax, (5) internal audit, (6) corporate planning/development \& R\&D en (7) government \& public relations. Zie hierover M.G. Baaij, T.J.M. Mom, F.A.J. van den Bosch \& H.W. Volberda, Why do multinational corporations relocate core parts of their corporate headquarters abroad? Long Range Planning (48) 2015, p. 46-58.

17. Het betreft (inclusief vermelding positie Global Fortune 500): 3 Royal Dutch Shell; 24 EXOR Group; 123 Airbus Group; 127 Royal Ahold Delhaize; 167 Unilever; 302 Louis Dreyfus Company; 310 ING Group; 316 LyondellBasell Industries; 446 Randstad Holding; 467 Heineken Holding; 483 Rabobank Group; 494 Achmea.

18. Zie bijv. WFR, afl. 7253 .

19. Zie www.cpb.nl/sites/default/files/omnidownload/CPB-Beantwoor ding-vragen-verschillen-Regeerakkoord-en-doorrekening-CPB.pdf, geraadpleegd op 17 juli 2020.

20. Zie p. 28 van het rapport. afwezigheid van dividendbelasting denk ik wel degelijk een aspect zijn dat de vestigingskeuze beïnloedt, nu dit van belang kan zijn voor de positie van beleggers en dat aspect bij de vestigingskeuze een factor zou kunnen zijn. ${ }^{21}$

\subsection{Adviezen commissie}

De commissie merkt als eerste op dat internationale samenwerking de belangrijkste weg is naar een goed functionerend internationaal belastingsysteem, waarin ongewenst strategisch gedrag van multinationale ondernemingen zo goed mogelijk wordt voorkomen. De commissie formuleert in dat kader een aantal punten waar Nederland zich sterk voor zou moeten maken bij het maken van internationale afspraken. Onder meer wordt aanbevolen om te streven naar:

1. een vorm van consolidatie van de grondslag;

2. toewijzingsregels die leiden tot minder manipulatie;

3. een minimumtarief, zodat de prikkel tot belastingconcurrentie wordt verminderd;

4. onderzoek of meer winsttoerekening aan marktlanden passend is bij een digitaliserende economie;

5. beperking van de fiscale bevoordeling van vreemd vermogen; en

6. bindende arbitrage, voor alle betrokken landen, om dubbele belastingheffing te voorkomen.

Om de geïdentificeerde knelpunten aan te pakken die kunnen bijdragen aan een onevenwichtige belastingafdracht van multinationals, adviseert de commissie een basisvariant van maatregelen die leiden tot grondslagverbredingen in de $\mathrm{Vpb}$ met oog voor het vestigingsklimaat. De maatregelen van de basisvariant zijn gericht op het bereiken van twee doelstellingen:

1. het creëren van een ondergrens in de $\mathrm{Vpb}$ voor bedrijven met winstgevende activiteiten in Nederland; en

2. het elimineren van verschillen (mismatches) met het buitenland.

Om te komen tot een ondergrens stelt de commissie voor om de jaarlijkse verliesverrekening (zowel de voorwaartse als de achterwaartse verliesverrekening) tot ten hoogste $50 \%$ van de belastbare winst van het jaar voor alle winst boven EUR 1 miljoen te maximeren, onder gelijktijdige invoering van een in de tijd onbeperkte voorwaartse verliesverrekeningstermijn. Deze limitering van het in aanmerking te nemen verlies is vooral geïspireerd op regelingen in omringende landen. Opmerkelijk, gelet op de doelgroep waar het rapport op mikt, is dat deze maatregel daarmee niet alleen multinationals treft, maar alle belastingplichtigen met een jaarwinst van meer dan EUR 1 miljoen per jaar. Daar zou nog eens goed naar moeten worden gekeken of dat wel wenselijk is. Voorts adviseert de commissie om de aftrek van niet-doorbelaste aandeelhouderskosten te beperken tot een (nader te bepalen) maximumpercentage van de belastbare winst, in combinatie met een doelmatigheidsdrempel. Aandeelhouderskosten zien onder andere op de door een hoofdkantoor gedragen kosten van het

21. De commissie lijkt dat overigens ook te onderkennen. Zie hierover p. 28 van het rapport. 
opstellen van de jaarrekening, de uitgifte van aandelen, de activiteiten van de raad van commissarissen en corporate governance. Voorts wordt aanbevolen om te onderzoeken of de aftrek van royalty's in groepsrelaties beperkt moet worden tot een (nader te bepalen) maximumpercentage van de belastbare winst, eventueel in combinatie met een doelmatigheidsdrempel. Ten slotte stelt de commissie voor om de aftrek van het saldo van rente en hoofdkantoorkosten en/of royalty's tot een gezamenlijk bedrag van bijvoorbeeld $50 \%$ van een gezamenlijke grondslag te beperken. De verschillende afzonderlijke maatregelen kunnen bijdragen aan een ondergrens in de Vpb. Dit laatste voorstel bewaakt de ondergrens steviger door een maximum te stellen aan de gezamenlijke aftrek van alle kosten waar de afzonderlijke maatregelen op zien.

In het kader van het elimineren van mismatches met het buitenland doet de commissie ook een aantal voorstellen. Zo wordt voorgesteld om de bestaande CFC-regels effectiever te maken door onder andere de door de Controlled Foreign Company (CFC) uitgekeerde winsten te belasten en de uitzondering voor wezenlijke economische activiteiten aan te passen. Daardoor zou het onder meer niet meer mogelijk zijn om aan de toepassing van de CFC-regels te ontkomen door voor het jaareinde het besmette inkomen door de CFC als dividend uit te laten keren. ${ }^{22}$ Voorts wordt voorgesteld om het arm's length-beginsel niet toe te passen indien dit beginsel leidt tot een verlaging van de belastbare winst in Nederland, voor zover het andere land dat bij de transactie betrokken is de correctie niet in zijn grondslag betrekt (informeel kapitaal). Het niet toepassen van het arm's length-beginsel zou voor de praktijk grote impact hebben. Volgens de commissie is daar aanleiding toe, omdat Nederland met deze zogenoemde 'downward adjustment' internationaal uit de pas loopt. Ook is voorgesteld de afschrijving op vermogensbestanddelen die binnen concern zijn overgedragen in aftrek te beperken, voor zover de afschrijving ziet op de stille reserves in het vermogensbestanddeel die bij de overdracht niet voldoende belast zijn geweest. Het is de vraag of de situatie waarin het omgekeerde zich voordoet - dat wil zeggen de situatie dat in het buitenland over de winst belasting wordt geheven - dan ook niet moet worden meegenomen. Dient Nederland in tegenovergestelde situaties dan niet (in beginsel) een tegemoetkoming te geven? Dat lijkt evenwichtig.

Voorts biedt de commissie ook een aantal aanvullende maatregelen ter overweging aan, waarover binnen de commissie echter geen consensus bestaat. Genoemd wordt onder meer het aanscherpen van de bestaande earnings stripping-maatregel met betrekking tot rente door verlaging van het aftrekbare rentesaldo van 30\% naar 25\% van de EBITDA. Dat lijkt overigens wat willekeurig. De fundamentele vraag hierbij is: Moet je de aftrek van rentekosten aan banden leggen? Is dit de juiste

22. CFC-wetgeving is fiscale wetgeving waarmee men wil voorkomen dat belastingplichtigen hun inkomen laten neerslaan in brievenbusvennootschappen in het buitenland, met name belastingparadijzen. route? ${ }^{23}$ Ook de beperking van de aftrek van rente die samenhangt met de aankoop van deelnemingen (dichten 'Bosal-gat') wordt aangehaald. ${ }^{24}$ Verder wordt onder meer genoemd uitbreiding van artikel 10a Wet VPB 1969, dat de aftrek van rente beperkt, en beperking van de aftrekbaarheid van alle soorten betalingen binnen concern die in het ontvangende land onvoldoende belast zijn. Daarnaast wordt ook invoering van een unilaterale digitaledienstenbelasting aangestipt.

Ten slotte doet de commissie enkele suggesties voor mogelijk compenserende maatregelen voor het vestigingsklimaat. Over de wenselijkheid van deze maatregelen bestaat evenwel eveneens geen consensus binnen de commissie. Genoemd zijn onder andere verlaging van het tarief voor de $\mathrm{Vpb}$, temporisering van de aftrek van liquidatie- en stakingsverliezen en afschaffing van het aftrekverbod op aan- en verkoopkosten deelnemingen.

\section{Nadere analyse van het rapport}

De motie Omtzigt c.s. verzocht een commissie van deskundigen in te stellen die adviseert over maatregelen om de belastingheffing over winsten van multinationals eerlijker te maken, met inachtneming van het feit dat Nederland aantrekkelijk blijft voor Nederlandse hoofdkantoren. ${ }^{25}$ De motie Omtzigt c.s. lijkt daarmee uit te gaan van het feit dat de belastingheffing van multinationals nu niet voldoende eerlijk is, omdat ondernemingen met een Nederlands hoofdkantoor niet in alle gevallen (voldoende) belasting betalen over de in Nederland behaalde winst. Voor het feit dat multinationals met hun hoofdkantoor in Nederland geen of weinig Vpb betalen over hun in Nederland behaalde productie- en verkoopwinst kan evenwel een logische en legitieme verklaring bestaan. Ten eerste is relevant dat de Nederlandse productieen verkoopwinst van de grote multinationals doorgaans slechts een bescheiden aandeel uitmaakt van de totale concernwinst, hetgeen een verklaring kan zijn voor de geringe belastingafdracht. Voorts wijs ik op de keuze van de wetgever om liquidatieverliezen op deelnemingen aftrekbaar te laten zijn, om dubbele belasting te voorkomen. Dat er geen of weinig Vpb wordt betaald, heeft kortom ook te maken met keuzes die de wetgever in het verleden heeft gemaakt. Daarbij geldt denk ik dat als die keuzes niet meer als wenselijk worden aangemerkt, het aan de wetgever is om die keuzes te heroverwegen. ${ }^{26}$

23. Zie hierover ook E.C.C.M. Kemmeren, Renteaftrek is niet het probleem in de vennootschapsbelasting; wel het niet-belasten van rente!, WFR $2009 / 401$.

24. HvJ EG 18 september 2003, C-168/01, ECLI:EU:C:2003:479 (Bosal Holding BV/Staatssecretaris van Financiën). De Nederlandse regel dat kosten van buitenlandse deelnemingen niet aftrekbaar zijn, is in strijd met EG-recht, zo werd geoordeeld.

25. Kamerstukken II 2018/19, 35110, nr. 11.

26. Uit de Miljoenennota 2020 blijkt dat het kabinet heeft besloten het initiatiefwetsvoorstel van GroenLinks, SP en PvdA over te nemen. Dit wetsvoorstel leidt tot een inperking van de liquidatie- en stakingsverliesregeling in de $\mathrm{Vpb}$. 
De commissie lijkt dit ook te onderkennen. Zo merkt de commissie op over de eerlijke belastingheffing dat het begrip 'eerlijk' een breed begrip is en veel perspectieven omvat. ${ }^{27} \mathrm{Zo}$ wordt het als oneerlijk ervaren, zo merkt de commissie op, dat de Wet VPB 1969 internationaal opererende bedrijven mogelijkheden biedt die nationale bedrijven niet kunnen gebruiken. Dit wordt veroorzaakt door het feit dat internationaal opererende ondernemingen door de complexiteit van de $\mathrm{Vpb}$ mogelijkheden hebben om hun wereldwijde belastingafdracht te verminderen. Hierbij kan worden gedacht aan het gebruik maken van verschillen in belastingregimes tussen landen en aan de mobiliteit van bijvoorbeeld intellectueleeigendomsrechten. ${ }^{28}$

Als we naar de cijfers kijken, dan lijkt er weinig aan de hand. Het antwoord op de vraag hoeveel $\mathrm{Vpb}$ multinationals betalen in verhouding tot andere soorten bedrijven luidt, zo volgt uit het rapport, dat die relatie over de periode 2010-2017 stabiel is. Multinationals nemen in 2017 EUR 11,7 miljard van de $\mathrm{Vpb}$-afdracht voor hun rekening, ofwel $51 \%$ van het totaal. Over de periode 2010-2017 is het beeld grofweg hetzelfde. De redactie van Vakstudie Nieuws trekt aldus uit het rapport de conclusie dat multinationals in het algemeen niet minder belasting betalen over hun winst dan andere ondernemingen. ${ }^{29}$ Hier valt mijns inziens wel wat op af te dingen. Ook de commissie plaatst hier enkele kanttekeningen bij. ${ }^{30}$ Ten eerste bieden de Nederlandse aangiftedata geen inzicht in hoeveel belasting Nederlandse bedrijven wereldwijd betalen, noch in de wijze waarop deze winst en de betaalde belasting verdeeld zijn over verschillende landen. ${ }^{31}$ Dit is relevant, omdat ondernemingen binnen het huidige stelsel mogelijkheden hebben winsten te verschuiven naar laagbelastende landen zonder substantiële wijzigingen in de investeringsstructuur. ${ }^{32}$ De tweede kanttekening is dat het op basis van de beschikbare cijfers niet mogelijk is om de effectieve druk in verhouding tot de commerciële winst te berekenen. Zo kunnen er grote verschillen zitten tussen de commerciële en fiscale winst door de innovatiebox, eventuele kwijtscheldingswinst en liquidatieverliezen van deelnemingen. Een derde kanttekening bij de uitkomsten is dat de gemiddelde belastingdruk een vertekend beeld kan geven van de belastingdruk op individuele bedrijven, omdat de spreiding tussen bedrijven enorm is. Zo kan het voorkomen dat individuele bedrijven door verschillende aftrekmogelijkheden meerdere jaren geen $\mathrm{Vpb}$ betalen, terwijl

27. Zie p. 18 van het rapport.

28. Zie p. 18 van het rapport.

29. V-N 2020/19.6

30. Zie p. $48-49$ van het rapport.

31. Zie p. 58 van het rapport.

32. ATAD (Anti Tax Avoidance Directive) bevat wel regels om dubbele niet-belasting als gevolg van bepaalde mismatches tegen te gaan, maar de overheveling van winst naar laagbelastende landen blijft mogelijk. In het publieke consultatiedocument 'Addressing the tax challenges of the digitalisation of the economy', dat op 13 februari 2019 door de OESO is gepubliceerd, wordt daarom een 'global anti-base erosion' (GLOBE)voorstel gedaan. Zie www.oecd.org/tax/beps/public-consultationdocument-addressing-the-tax-challenges-of-the-digitalisation-of-theeconomy.pdf, geraadpleegd op 19 juli 2020. zij wel (commercieel) winstgevende activiteiten hebben. Inderdaad blijkt uit het rapport dat verrekende verliezen uit het verleden een grote rol spelen: $13 \%$ van de bedrijven uit de dataset lijdt over de gehele onderzoeksperiode verlies in Nederland. Voor 38\% van de bedrijven geldt dat zij over de onderzochte periode meer verliezen leden dan winsten maakten. Er is dus sprake van een groep bedrijven die structureel fiscaal verlies lijdt. Een interessante vraag is dan of die bedrijven ook commercieel verliesgevend zijn. De conclusie is kortom dat er nog veel onzekerheid over bestaat of sprake is van een eerlijke belastingheffing.

De commissie adviseert daarom nader onderzoek te doen naar de oorzaak hiervan. Ook dient nader onderzoek te worden verricht naar het belang van royalty's hierbij, naar het rendement op in Nederland geïnvesteerd kapitaal en naar de verschillen tussen fiscale en commerciële winstbepaling bij multinationals. Voorts adviseert de commissie om:

1. bedrijven te gaan verplichten voortaan in alle gevallen de commerciële winst in Nederland te rapporteren; en

2. in internationaal verband te blijven samenwerken om de kwaliteit van landenrapporten te verbeteren en toe te werken naar publieke Country-by-Country Reporting.

Het betreft waardevolle aanbevelingen, waarbij ik mij afvraag of de rapportageverplichting van de commerciële winst is bedoeld als een fiscaal-administratieve verplichting (moet de inspecteur toezien op de naleving van de rapportering van de (juiste) commerciële winst, en zo ja, gelden er dan fiscale boetes bij niet-naleving?). De vraag is evenwel of met deze voorstellen de problemen worden opgelost. Zal hierdoor duidelijk worden welke multinational geen fair share aan $\mathrm{Vpb}$ betaalt en waar dat door wordt veroorzaakt? Ik betwijfel dat. ${ }^{33}$ Niettemin is het denk ik zeker een stap in de goede richting. Het leidt in elk geval tot meer relevante dataverzameling en daarmee tot meer transparantie, hetgeen weer tot nieuwe inzichten kan leiden.

Een ander element van eerlijke belastingheffing ziet op de vraag waar de $\mathrm{Vpb}$ neerslaat. In dat kader wordt in het rapport terecht aangestipt dat uiteindelijk alle belastingen gedragen worden door individuen, ook de door multinationals betaalde winstbelasting. Het zijn de consumenten, werknemers en

33. Op grond van het actieplan tegen 'Base Erosion and Profit Shifting' (BEPS) moeten alle multinationals met een geconsolideerde omzet van ten minste EUR 750 miljoen een landenrapport (country-by-country-rapport) opstellen. De belastingdiensten wisselen deze landenrapporten vervolgens uit. Zo kunnen belastingdiensten bij multinationals beter de risico's op het gebied van belastingontwijking beoordelen. Daarnaast is besloten dat jaarlijks gegevens op basis van landenrapporten worden gepubliceerd, ten behoeve van economische en statistische analyses van de activiteiten van multinationals en belastingontwijking. De jaarlijkse publicatie van de OESO 'Corporate Tax Statistics' bevat in 2020 voor het eerst data uit deze gegevens, op basis van data uit 26 landen over het belastingjaar 2016. Er gelden twee vereisten voor Country-by-Country Reporting: (1) een groepsomzet van meer dan EUR 750 miljoen en (2) internationale vertakking. Voor kleinere multinationals geldt dit kortom niet. 


\section{Maandblad \\ Ondernemingsrecht}

aandeelhouders van het bedrijf die de $\mathrm{Vpb}$ uiteindelijk dragen. ${ }^{34}$ Vanuit dat perspectief kan eerlijke belastingheffing betekenen dat de bijdrage aan de schatkist gebaseerd is op het draagkrachtbeginsel of het profijtbeginsel. Oftewel, moet het gaan om de te heffen belasting bij de onderneming met als doel om de achterliggende aandeelhouder voldoende te belasten (draagkracht), of gaat het erom dat voldoende en regelmatig belasting geheven moet worden bij het bedrijf door de voordelen die de onderneming heeft van de Nederlandse publieke voorzieningen (profijt)? ${ }^{35}$ Een laatste element waar rekening mee moet worden gehouden, is stabiliteit en voorspelbaarheid van de toepasselijke fiscale regelgeving, omdat ondernemingen hun beslissingen op het beleid van de overheid afstemmen. ${ }^{36}$

Afbakenen van wat een eerlijke belastingheffing is, is kortom nog niet zo eenvoudig. Zo zou bijvoorbeeld een aftrekbeperking van hoofdkantoorkosten en liquidatieverliezen tot dubbele belasting kunnen leiden, hetgeen Nederland fiscaal onaantrekkelijker zou maken. Lezing van het rapport en de gesuggereerde maatregelen doet sowieso de indruk ontstaan dat het creëren van extra heffingsopbrengst meer de nadruk had dan het behoud van het vestigingsklimaat. Op p. 98 van het rapport stelt de commissie zelf evenwel dat de zeven in de zogenoemde basisvariant voorgestelde opties bestaan uit maatregelen die balans weten te houden in de zoektocht naar grondslagverbreding met oog voor het vestigingsklimaat. Hier kunnen naar mijn mening enige vraagtekens bij worden geplaatst, nu elders in het rapport de commissie immers stelt dat er nog veel onzekerheid bestaat omdat er te weinig informatie beschikbaar is. Een andere vraag die denk ik beantwoord moet worden, is wat de consequenties zijn van voorgestelde maatregelen op een samenleving die met COVID-19-omstandigheden te maken heeft. Zou Nederland een economische recessie tegemoetgaan, dan is het de vraag of bijvoorbeeld verbreding van de heffingsgrondslag en limitering van het bedrag dat als verlies verrekend kan worden thans wel nagestreefd moeten worden.

Wat mist in het rapport is toetsing van de voorgestelde maatregelen aan 'eerlijkheid'. De maatregelen lijken (met name) te zijn gebaseerd op de wens om grondslagverbreding te bereiken zonder al te veel afbreuk te doen aan het vestigingsklimaat. Maar waarom die maatregelen eerlijk zijn, wordt niet duidelijk. Waarom is bijvoorbeeld de beperking van de verliesverrekening eerlijk? De commissie noemt enkele beginselen, zoals draagkracht- en profijtbeginsel (zie p. 9). Het beperken van de verliesverrekening staat daar op gespannen voet mee. De vraag is voorts ook waarom de grondslagverbreders vanuit het perspectief van eerlijkheid nodig zijn.
34. Zie p. 18 van het rapport.

35. Zie p. 18 van het rapport.

36. Zie p. 19 van het rapport.

\section{Conclusie}

Het antwoord op de vraag of het rapport een goede balans heeft weten te vinden tussen een eerlijker $\mathrm{Vpb}$ en het vestigingsklimaat valt denk ik niet goed te geven. Dit komt met name omdat de commissie door de fiscale geheimhoudingsplicht niet over voldoende relevante gegevens over de belastingafdracht van multinationals kon beschikken. De voorstellen die de commissie doet, lijken daardoor vooral te zijn gebaseerd op een analyse van de knelpunten in de $\mathrm{Vpb} .{ }^{37}$ Voor die keuze kan zeker begrip worden opgebracht. In dat kader doet de commissie mijns inziens veel waardevolle voorstellen en bevat het rapport veel nuttige inzichten waar verder over nagedacht kan worden. Het woord is nu aan het (volgende) kabinet. Ik ben benieuwd.

37. Dit lijkt ook een bewuste keuze. Zie daarover het rapport op p. 17. Ik citeer: 'Omdat de motie vraagt om "eerlijkere" belastingheffing bij multinationals hanteert de Commissie als uitgangspunt dat de maatregelen vooral moeten leiden tot een effect op de belastingheffing op bedrijven met grensoverschrijdende activiteiten', alsmede 'De Commissie laat echter niet na met een bredere blik naar het stelsel van winstbelasting te kijken. Ze zal daarom ook adviseren over de Nederlandse inzet in het internationale speelveld. Hieronder valt bijvoorbeeld grondslag harmonisatie in de EU en BEPS 2.0. Hierbij besteedt de Commissie aandacht aan de vraag hoe zich de internationale ontwikkelingen verhouden tot de autonomie van Nederland op het gebied van de Vpb' en 'Om te komen tot concrete voorstellen is het van belang om de problematiek nader te onderzoeken. Waarin liggen de oorzaken van het geconstateerde maatschappelijke probleem en het functioneren van de Vpb?' Zie voorts ook hoofdstuk 6 van het rapport. 